\section{Acknowledgments}

A.N.H. was supported by a Newcastle University Hospitals' Scientific and Research Committee Grant.

\section{References}

CARoli, S. \& Couineaud, C. (1958) Une affection nouvelle, sans doute congénitale, des voies biliaires; la dilatation kystique unilobaire des canaux hépatiques. Semaine des Hôpitaux de Paris, 14, 136.

LAZAR, A.J. (1966) Cirrhosis, Gram-negative sepsis and chloramphenicol toxicity. American Journal of Gastroenterology, 45, 29.
Mujeted, L., Glenn, F. \& Evans, J.A. (1971) Communicating cavernous ectasia of the intrahepatic ducts (Caroli's disease). American Journal of Roentgenology, 113, 21.

Scioli, C., Fiorentino, F. \& SAsso, G. (1972) Treatment of Salmonella typhi carriers with intravenous ampicillin. Journal of Infectious Diseases, 125, 170.

Smithives, T., Hyams, P.J. \& Patiol, J.J. (1971) Gentamicin and ampicillin in human bile. Journal of Infectious Diseases. 124, 106.

WALdRAM, R.M.R., VAHRMAN, J. \& Williams, R. (1975) Salmonella heidelberg infection in Caroli's syndrome. Gastroenterology. 68, 151.

\title{
Systemic mastocytosis-central nervous system features and lymphographic demonstration of lymph node involvement
}

\author{
B. W. HANCOCK \\ M.B., Ch.B., D.C.H., M.R.C.P. \\ P. DANDONA \\ M.B., B.S., M.R.C.P., D.Phil. (Oxon) \\ D. C. Cumberland* \\ M.B., Ch.B., D.M.R.D., F.F.R. \\ J. A. JARRATT $\dagger$ \\ M.B., Ch.B., M.R.C.P. \\ Academic Division of Medicine, *Department of Radiology, The Royal Hospital, Sheffield S1 3SR, and \\ †Department of Clinical Neurophysiology, Fulwood Annexe, Sheffield S10 3TD
}

\begin{abstract}
Summary
Systemic mastocytosis is uncommon. A patient is reported with many of the characteristic lesions of this disorder but with two features not before describedthe occurrence of mixed pyramidal and neuromyopathic neurological signs and the demonstration of lymph nodes with abnormal architecture by lymphography.

\section{Case report}

A female patient (Fig. 1) presented in 1967 aged 54 years with cutaneous urticaria pigmentosa (confirmed by skin biopsy). In 1972 splenic enlargement was noted but was not investigated. She was admitted to hospital in May 1974 with a history of ill health and weight loss of $35 \mathrm{~kg}$ over the previous year. On examination she was emaciated, anaemic and showed characteristic skin lesions of urticaria pigmentosa. Liver and spleen were each enlarged to $12 \mathrm{~cm}$ below costal margins. Extensive investigations gave these abnormal results: haemoglobin $9 \cdot 5 \mathrm{~g} / 100$ $\mathrm{ml}$ (red cells microcytic and normochromic); leucocyte count $8,000 / \mathrm{mm}^{3}(10 \%$ monocytes $)$; platelet count $60,000 / \mathrm{mm}^{3}$; ESR (Westergren) $45 \mathrm{~mm} / \mathrm{hr}$; circulating heparin detected $(0 \cdot 3 \mathrm{u} . / \mathrm{ml}$ by specific
\end{abstract}

heparin assay); red cell half-life (after ${ }^{51} \mathrm{Cr}$-labelling) reduced to 14.6 days; serum iron and total iron binding capacity low ( 9 and $48 \mu \mathrm{mol} / 1$ respectively); bone marrow and bone infiltrated by mast cells; serum alkaline phosphatase elevated $(410 \mathrm{u}$./l) serum 5 nucleotidase elevated to $38 \mathrm{u} . / 1$, serum hepatocellular enzymes uniformly elevated; skeletal survey showed characteristic sclerotic changes; and bipedal lymphogram demonstrated abnormal iliac and paraaortic lymph nodes (see below).

At this stage the patient was treated with prednisolone ( $20 \mathrm{mg}$ daily). The size of the liver and spleen diminished; the ESR fell to $16 \mathrm{~mm} / \mathrm{hr}$ and haemoglobin rose to $12 \mathrm{~g} / 100 \mathrm{ml}$. However, over the next few months she developed weakness of arms and legs which progressed even though the dosage of prednisolone was reduced to $5 \mathrm{mg}$ daily. There was also episodic urinary and faecal incontinence. Examination revealed marked proximal weakness in addition to bilateral diffuse loss of power in the pyramidal distribution. The deltoid, biceps brachii, quadriceps femoris and hamstring muscles were wasted but no fasciculation was seen. Some incoordination of the legs was present, probably attributable to her weakness. The jaw jerk and other 


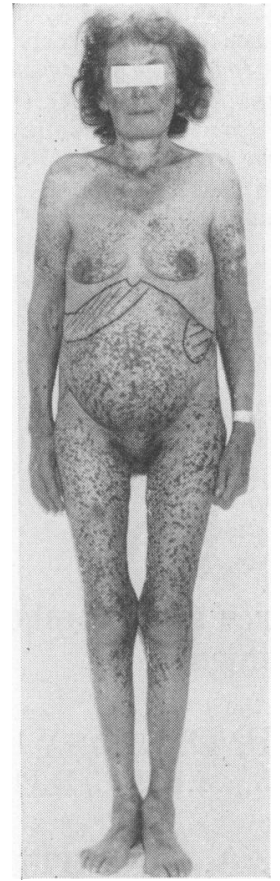

FIG. 1. Photograph of patient showing cutaneous urticaria pigmentosa and hepato splenomegaly.

reflexes were pathologically brisk and the palmomental reflex was present; the plantar responses were flexor. Joint position and vibration sensation were impaired peripherally with some loss of pain and temperature sensation in all limbs and over the trunk. Myelogram, cerebrospinal fluid examination, electroencephalogram and brain scan were normal. Other electrophysiological results, given in detail below, demonstrated a proximal myopathy and a co-existent sensorimotor peripheral neuropathy, which appeared to be mainly if not entirely axonal in type.

The following muscles were examined by electromyography: right deltoid, right biceps brachii, right triceps brachii, right vastus medialis, and right extensor digitorum brevis. None had been biopsied. All showed some reduction in the pattern at maximal effort, the changes being most marked in right extensor digitorum brevis where there was a pattern of discrete activity (Fig. 2). These findings indicate a motor neuropathy. In right vastus medialis and, to a lesser extent, in right biceps brachii motor units of brief duration were found (Fig. 3). Although lack of trigger and delay facilities precluded precise quantitation of these they were present in sufficient numbers to make the diagnosis of a co-existent proximal myopathy of mild to moderate severity. Motor units were otherwise unremarkable and, in parti-

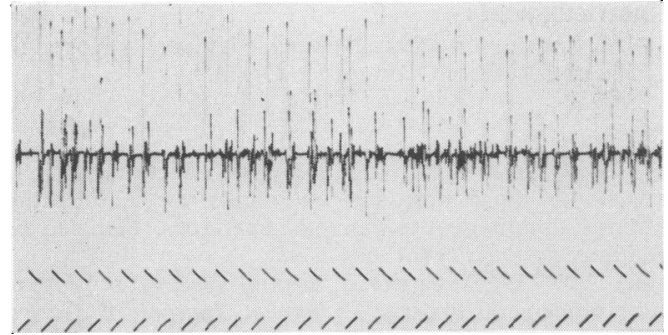

Fig. 2. Right extensor digitorum brevis. Pattern at maximal voluntary effort. Calibration signal: $1 \mathrm{mV}$ at $100 \mathrm{msec}$ intervals.

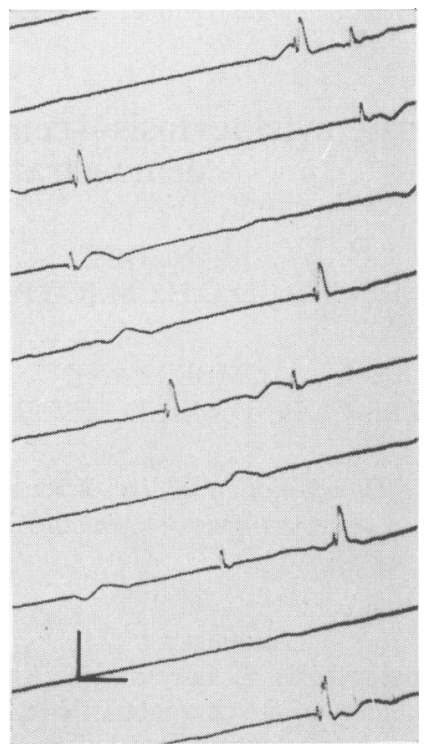

FIG. 3. Right biceps brachii. Individual motor units recorded at weak voluntary effort. Calibration: $200 \mu \mathrm{V}$ by $10 \mathrm{msec}$.

cular, there was no evidence of regeneration. No spontaneous activity was seen.

The following nerve conduction studies were performed: right sural, right peroneal (motor and sensory study), right median (distal sensory study only), and right ulnar (distal sensory study only). A concentric needle electrode was used to record the evoked muscle action potentials, otherwise surface electrodes were used throughout. Sensory action potentials were averaged by computer. A sensory action potential could not be recorded from either the right sural nerve or the right peroneal nerve. The amplitude of the sensory action potential recorded at the wrist during stimulation of right digit II $(7 \mu \mathrm{V})$ was at the lower limit of the normal range; that obtained during stimulation of right digit $\mathrm{V}(6 \mu \mathrm{V})$ was also at the lower limit of the 


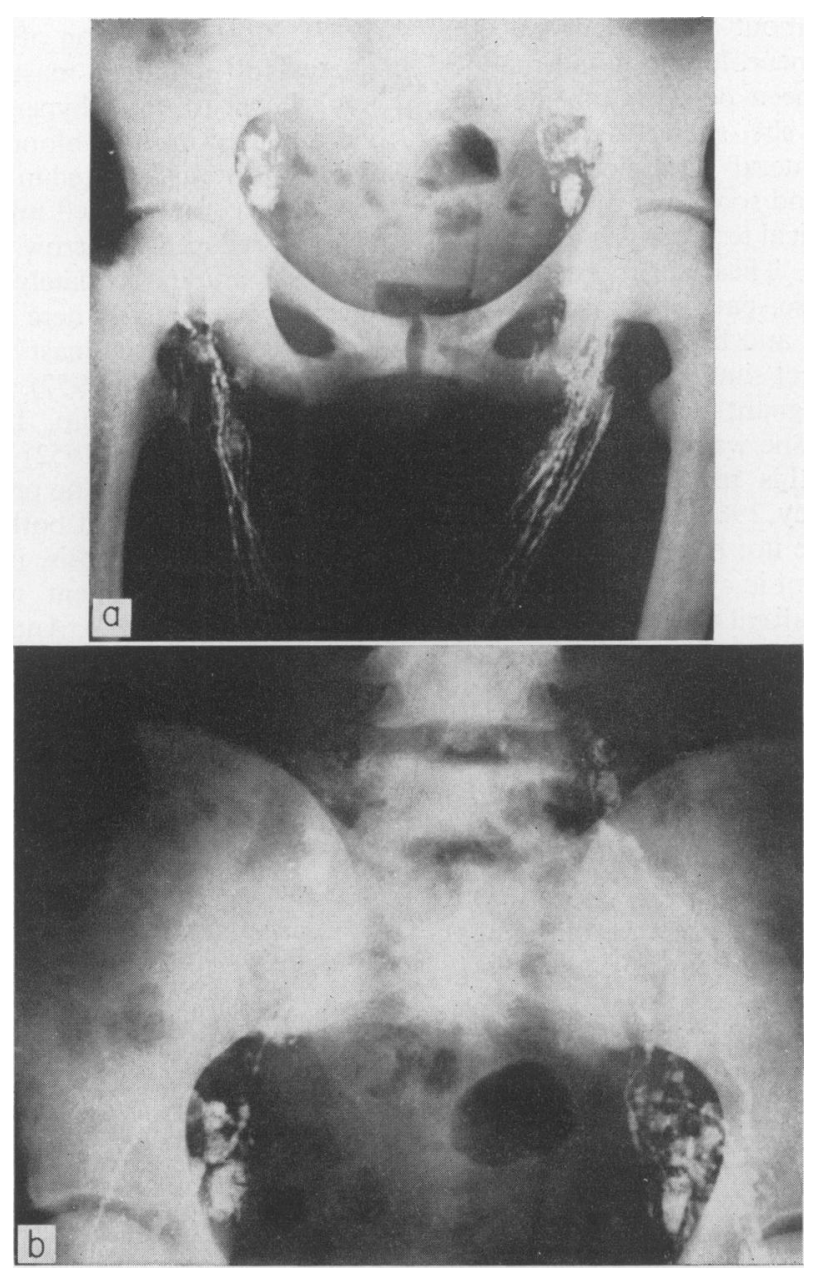

FIG. 4 (a) Lymphogram demonstrating dilated lymphatics.

(b) 24-hr lymphogram film showing the irregular outline of the lymph glands and multiple marginal filling defects.

normal range. However, the associated maximal sensory conduction velocities $(50 \mathrm{~m} / \mathrm{sec}$ and $52 \mathrm{~m} / \mathrm{sec}$ respectively) were normal and the potentials were normal in form. The maximal motor conduction velocity in the right peroneal nerve $(43 \mathrm{~m} / \mathrm{sec})$ and the distal latency to right extensor digitorum brevis $(4 \cdot 2 \mathrm{msec})$ were also normal.

Histological examination of a muscle biopsy specimen showed generalized atrophy of muscle fibres. In the oxidative enzyme stains the type II fibres particularly were atrophied and many had a mottled appearance. There were also a few groups of atrophied fibres with a motor-unit type of distribution. The appearances were of a non-specific myopathy with evidence of a neurogenic component. Occasional mast cells were found between muscle fibres but there was no evidence of any other inflammatory reaction.

In January 1975 she developed gross abdominal ascites. No abnormal cells were found in the ascitic fluid (sp.g. 1.3; protein content $55 \mathrm{~g} / \mathrm{l}$ ). Repeated paracentesis and administration of frusemide and spironolactone have given symptomatic improvement. High dose prednisolone therapy has been restarted, again with reduction of spleen size and partial remission of disease progress.

\section{Discussion}

Mastocytosis, an abnormal proliferation of tissue mast cells, may involve skin, lymph nodes, viscera, bones and the entire reticulo-endothelial system (Gonella, 1967). 
The unusual feature about the patient was the presence of widespread neurological abnormalities which have not before been described in systemic mastocytosis. Clinically she showed evidence of proximal myopathy, bilateral pyramidal tract involvement, sensory loss and some loss of sphincteric control. Electrophysiological tests confirmed a mixed neuromyopathic picture. These features may be attributed either to diffuse, patchy intra-medullary infiltration of spinal cord and brain stem with mast cells or to an indirect effect similar to that observed in association with malignant disease (Wilkinson, Croft and Urich, 1971). She was treated with prednisolone and although this may cause myopathy (Afifi, Bergman and Harvey, 1968) such disseminated neurological findings have not been described.

Lymph node involvement in systemic mastocytosis may be regional or generalized (Havard and Bodley Scott, 1959). Bipedal lymphography in the patient demonstrated dilated lymphatics (Fig. 4a) some of which still contained contrast after $24 \mathrm{hr}$ (Fig. 4b) indicating obstruction. The iliac and paraaortic glands to the level of L4 were normal in size but showed multiple marginal filling defects of varying size, giving the glands an irregular outline (Fig. 4b). The changes do not resemble those seen in the lymphomas or in secondary carcinoma but similar appearances are sometimes present in patients with collagen-vascular disease.

Only one other report has been found of lymphography in mastocytosis (Munro, Craig and Feiwel, 1969). The changes described are quite different from those seen in the present patient with 'symmetrically enlarged glands of normal architecture but a greatly thickened cortex and medulla'. The typical lymphographic changes of mastocytosis are therefore not known and future reports will be of great interest.

Hepato-splenomegaly occurs with widespread mast cell involvement of the reticulo-endothelial system. Splenic enlargement may be due to portal hypertension secondary to hepatic infiltration and fibrosis. This patient had massive hepato-splenomegaly. She also developed ascites possibly from portal hypertension although the high protein content and specific gravity of the ascitic fluid were more in keeping with mast cell infiltration of the peritoneum.

Haematological disturbance is common-anaemia, leucopenia, monocytosis, thrombocytopenia and bleeding diathesis have all been described (Gonella,
1967). Mast infiltration of bone marrow, a marrow depressant action of mast cell released substances (e.g. heparin) and hypersplenism have all been incriminated in these blood abnormalities. Circulating heparin was detected in the patient, bone marrow infiltration was marked and red cell survival significantly reduced. Marrow involvement and hypersplenism would adequately explain her anaemia and thrombocytopenia. There were no haematological changes of tissue mast cell leukaemia (Efrati, Klajman and Spitz, 1957).

The skin (Nettleship, 1869) and bone (Sagher, Cohen and Schorr, 1952) changes of mastocytosis are well recognized. The present patient had characteristic involvement of both tissues.

Systemic mastocytosis, particularly with reticuloendothelial involvement may be progressive and lethal (Gonella, 1967). Antimitotic drugs and radiotherapy have not proved helpful in treatment and whilst corticosteroid therapy may give temporary benefit this is not curative (Sagher and Even-Pas, 1960). Certainly, the condition of the patient described here continues to deteriorate even though there has been partial response to steroid therapy.

\section{Acknowledgments}

We are grateful to $\mathrm{Dr}$ W. R. Timperley for his comments on the muscle histology and to Professor J. Richmond and Dr C. W. H. Havard for helpful advice. The technical help of Mr A. K. Tunstill and staff of the Photographic Department, Royal Hospital, is also gratefully acknowledged.

\section{References}

Afifi, A.K., Bergman, R.A. \& Harvey, J.C. (1968) Steroid myopathy. Johns Hopkins Medical Journal, 123, 158.

Efrati, P., Klajman, A. \& SpITz, H. (1957) Mast cell leukaemia-malignant mastocytosis and blood basophilia. Blood, 12, 869.

Gonella, J.S. (1967) Mast cell disease. Progress in Clinical Cancer, 3, 281.

Havard, C.W.H. \& Bodley ScotT, R. (1959) Urticaria pigmentosa with visceral and skeletal lesions. Quarterly Journal of Medicine, 28, 459.

Munro, D.D., Craig, O. \& Feiwel, M. (1969) Lymphangiography in dermatology. British Journal of Dermatology, 81,652 .

Nettleship, E. (1869) Rare forms of urticaria. British Medical Journal, 2, 323.

SAGHer, F., Cohen, C. \& SchorR, S. (1952) Concomitant bone changes in urticaria pigmentosa. Journal of Investigative Dermatology, 18, 425.

SAGHeR, F. \& Even-PAz, Z. (1960) Mastocytosis. In: Cutaneous Manifestations of Reticulo-Endothelial Granulomas (Ed. by S. M. Bluefarb), p. 268. Thomas, Illinois.

Wilkinson, M., Croft, P.B. \& URICH, H. (1967) The remote effects of cancer on the nervous system. Proceedings of Royal Society of Medicine, 60, 683. 